\title{
8. Utopias, ideal-types, paradigms, models and 'good practices': repertoire of conceptual tools for public administration?
}

\section{INTRODUCTION}

We have concluded the previous chapter with More's masterpiece which introduced the notion of utopia and utopian thinking as a way of practising teleological thinking in the study of public governance. In Aristotle's framework of the four causes (introduced in Chapter 2 and examined for application to PA in Chapter 6), this approach entails starting the analysis from the final cause - that is, the goal or end, the reason why something is brought about - to then turn to the other causes, like the material cause (what enables a thing to be transformed from a potentiality into actuality) and the efficient cause (the forces that bring about change). A utopian approach also entails taking as incipit of the analysis the potentiality (what might be, but does not yet exist in actuality), rather than actuality (what exists here and now).

At the opposite pole we can find the notion of a practice that works, a practice (too often and erroneously qualified as 'best' in much of the grey literature and consultancy papers) which exists in actuality and is predicated to produce certain effects, at least in the given context where it is operating. 'Best practices' or 'good practices', as they are often called, exist in actuality rather than in potentiality like utopias, and the starting point is the efficient cause: the causal mechanism which brings about the effect the practice produces. Conceptually, 'practices' can be seen to lie at the opposite pole than utopias: practices exist in actuality (here and now), utopias exist as potentials; practices are characterised primarily by a logic of efficient cause, utopias by a logic of final cause.

We can also consider there are other conceptual tools that enjoy currency in PA that are located at intermediate points in-between utopias and practices (see Figure 8.1). These are the notions of: model, ideal-type, and paradigm (definitions are provided later in the chapter as the concepts are introduced and examined in turn). In this chapter, we revisit these five notions - utopias, paradigms, 
ideal-types, models and practices - and their usages in PA in an integrated way. We argue that the combined use of these notions may be beneficial to the progress of PA, and we observe that over time in the PA debate attention may shift and the emphasis may be placed on one or the other of these notions to the risk of overlooking the others: we hope that revisiting in a joint way these conceptual tools for PA may enable scholars and practitioners to resort more systematically to the whole gamut, and to employ these conceptual tools in a complementary and integrated way for tackling complex public governance problems. We start from the notion of utopia and its possible usages in PA.

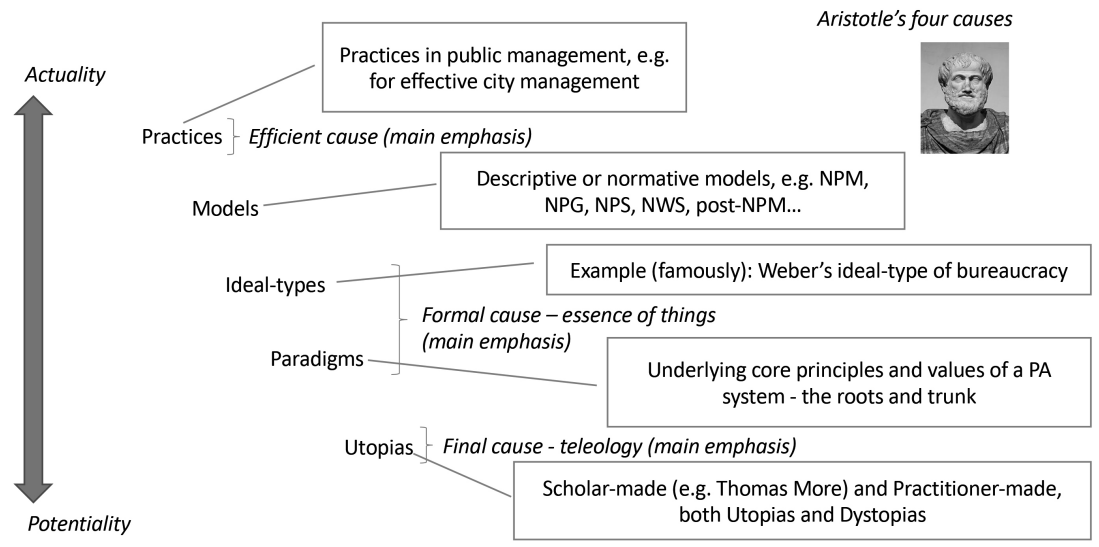

Figure 8.1 Gamut of conceptual tools and Aristotle's four causes

\section{UTILISING THE NOTION OF UTOPIA IN PA}

Is utopian thinking utilised in contemporary PA discourse? It is hard to answer such a question because it would demand wide-scope textual analysis of public discourses, and compellingly defining what exactly could be placed under the label of 'Utopian thinking'. However, a tentative, possibly provocative, statement put forward in this book is that, with a few notable exceptions (one definitely being the contribution by Bouckaert, 2020, aimed at reviving Utopian thinking in and for PA, also drawing on Achten et al., 2016; see also Jacoby, 2005), utopian thinking is limitedly used as a systematic conceptual tool for the critique and reforming of PA, and yet, at the same time, both utopias and dystopias surface copiously in contemporary PA debates.

Some of these utopias/dystopias are worked out by practitioners. As noticed by a practitioner intervening on the debate on the usage of utopias in PA, one recurrent utopia is the 'smart', small (mid-sized) city, socially inclusive, highly innovative and well-administered (Lucas, 2015). Interestingly, if we look at 
a network of (self-asserted) 'forward-looking' cities which was promoted between the end of the 1990s and the debut of the 2000s by the Bertelsmann Foundation (a German-based foundation active in supporting applied research in the field of public governance and management) and called 'The Cities of Tomorrow', ${ }^{1}$ it is worth noticing almost all of them were medium-sized cities. Since the 2010s, the main rhetoric revolves around the appealing label of 'smart cities'. It may be worth considering whether these notions of 'the cities of tomorrow' and the 'smart cities' are all utopias (dystopias?) floating around in disguised forms.

If the 'mid-sized smart city' might be an example of a practitioner-made utopia, two more categories may be envisaged: ${ }^{2}$ scholar-made utopias (and dystopias); and institutions-made utopias (dystopias). In both cases, unfortunately, dystopias may be more abundant than utopias. Starting from scholarly-made utopias/dystopias, one may think of 'governance without government': this might obviously be just a catchy slogan mainly coined to convey a strong message, but to the extent that government is imagined to be useless to good governance, it may swiftly translate into a utopia or, for those who think public administrative apparatuses and governmental action are necessary to good governance, in a dystopia. Certain depictions of the citizens as 'honest plus smart plus engaged', the citizen 'maker of good governance' also appear to display rather more the trait of blueprint utopia easily morphing into dystopia than providing an appropriate characterisation of real citizens (as perhaps shown by the rise of populism in the 2010s in the Western world and beyond). It may be noticed that these utopian/dystopian representations are far from the carefully crafted governance arrangements adopted by More's Island of Utopia to regulate the relationship between government and citizens.

Other examples of scholarly-made utopias are more thoroughly crafted and also more explicit in adopting utopian thinking as a conceptual tool. Garofalo and Geuras (2015) identify a number of utopias including 'a covenant between practitioners and scholars', which 'encompasses the hopes and concerns of public administration scholars and practitioners about their lack of connection with one another ... in which they collaborate to frame and resolve management and organizational problems' (Garofalo and Geuras, 2015, p. 86, drawing on Posner, 2009). This utopia is iconoclastic in its thrust to enable the critique of current ways of mutual engagement between practitioners and academics conceived as a means to identifying ways forward to better bridge PA scholars and practitioners.

There are, fortunately, a number of examples of scholarly-made utopias that point to constructive usages of utopian thinking as conceptual tool for critical analysis and forward-looking thinking. These include at least some of the contributions to envisioning the future of PA that came out of the Minnowbrook conferences (for the first Minnowbrook, see Marini, 1971; for 
the third Minnowbrook held in 2008, see O'Leary et al. 2010, amongst others), and ambitious research programmes like the 'European Perspectives on Public Administration' (EPPA): the Humboldt Foundation-sponsored project of the European Group for Public Administration (EGPA) led by Geert Bouckaert and Werner Jann (Bouckaert and Jann, 2020), which also developed probably one of the best wrought out and most self-conscious usages of the notion of utopia and utopian thinking in and for PA (Bouckaert, 2020). ${ }^{3}$

Turning to institution-made utopias, one obvious, and major, example are the Sustainable Development Goals (SDGs) of the United Nations. One might also wonder whether such ambitious charts of principles and goals are useful or useless utopias. The first set of the United Nations 'Millennium Development Goals' that were to be achieved by 2015 looked in a number of respects like a blueprint, which did not always allow for learning and adaptability, which did not cope with inherent contradictions or trade-offs, and which were hardly usable to consider critically the local circumstances as the point of departure for improvement and development. So, were those goals a useless utopia? Possibly but not necessarily. The 2015 version of the goals, the seventeen Sustainable Development Goals to be attained by 2030, may represent a different story. In fact, a more optimistic view sees them as one of the most ambitious collective undertakings of humankind ever attempted (to achieve a better world), underpinned by multilateralism and by a vision of humanity taking its destiny in its hands collectively (very much in line with Kant's framing of multilateralism as a condition for the attainment of conditions of peace in the world, as in Kant, 1795/2013, 'On Perpetual Peace'); and significantly, Sustainable Development Goals have been approved by all UN Member States. Seen in this way, the Sustainable Development Goals can be interpreted as positive utopias: a way of both challenging the current state of affairs in the world and of envisioning a world which is other from the extant one, a way of thinking teleologically starting from the ultimate goals to attain rather than the extant circumstances. In this sense, they might be interpreted as positive utopias, and not just as a form of 'Management by Objectives' (dys) topian list. As part of these utopias, Sustainable Development Goal number 16 concerning the development of strong and resilient public institutions enabling peace and justice might be interpreted as a collectively endorsed utopia inspiring PA scholars and practitioners alike to envisage paths for the betterment of PA.

There is a link, but also a clear distinction, between foresight and utopian thinking. Strategic and policy foresight and other forward-looking exercises developed by public institutions (as may be the case with think tanks or policy units, at times outside government but influential over it, at times embedded into the very administration of the core government, as it happens in some countries, or the supranational polity of the European Union: for example the 
European Political Strategy Centre of the European Commission, or the policy lab of the Joint Research Centre, again of the European Commission, which produces foresight studies and scenarios on the future of government and of citizen-government relations) are ultimately driven by an attempt at forecasting, at anticipating futures with diverse grades of likelihood and resemblance to the present. Utopian thinking deliberately breaks all the bridges with the extant state of affairs to enable re-thinking, a thinking afresh of how government and society could be organised.

From the perspective of the notion of utopia, we can revisit three other most famous concepts used in the field of PA as well as across the social and natural sciences: these are the notions of ideal-type, paradigm, and models - these notions have a huge history and range of usages: consistently with the purposes of the book, we confine this revisiting of the three notions to the application to the field of PA.

\section{REVISITING THE NOTIONS OF IDEAL-TYPE, PARADIGM, AND MODEL}

Given the significance for the PA debate, it may be worth distinguishing utopias from the notion of 'ideal-type', famously associated with the work of Max Weber. Interestingly, Weber mentions that ideal-types are in a sense a utopia:

It [the ideal type] is not a description of reality but it aims to give unambiguous means of expression to such a description ... An ideal-type is formed by the one-sided accentuation of one or more points of view and by the synthesis of a great many diffuse, discrete, more or less present and occasionally absent concrete individual phenomena, which are arranged according to those one-sidedly emphasized viewpoints into a unified analytical construct (Gedankenbild). In its conceptual purity, this mental construct (Gedankenbild) cannot be found empirically anywhere in reality. It is a utopia. (Weber, 1949, p. 90, emphasis added)

It should be noticed that here 'ideal' does not mean 'normative/prescriptive' (that is, something that ought to be achieved), it simply means that it is mental, and in its conceptual purity, this mental construct cannot be found empirically anywhere in reality. It is in this specific sense that Weber referred to it as utopia.

Ideal-types are culturally meaningful, value-laden representations of social phenomena, but yet, different to the utopias as delineated in the previous section of this chapter, ideal-types are not whole worlds 'other' from this world; rather, they keep their umbilical cord with the social phenomena, of which they represent a unified analytical construct. The ideal-type is not a description of reality but it aims to give unambiguous means of expression 
to such a description: its usefulness lies in that ideal-types can be used as yardsticks - investigators can arrive at interpretative understanding of a concrete empirical observation by comparing its differences with the initially constructed yardstick. Weber famously theorised the ideal-type of 'bureaucracy under legal domination' (that is, where legitimacy lies in the supremacy of the law, rather than in charisma or tradition).

The process of ideal-typing is a matter of imagining and contrasting the worked out analytical construct with experience: 'It is a matter here of constructing relationships which our imagination accepts as plausibly motivated and hence as "objectively possible" and which appear as adequate from the nomological standpoint' (Weber, 1949, p. 92, emphasis added). It has to do with generic patterns (behaviour and structure) of culturally significant features (that are necessary for understanding causal relationships, and are significant for the social scientist or a larger social-cultural group), which are given a unique meaning (these are indicated as the genetic features that make the ideal-type unique: an ideal-type is a unique 'creature' in the realm of the ideal). In this sense, Ideal-typing may be claimed to be an approach to theory building. The ideal-type is based on logical coherence, at logical and value (axiological) level, which entails that the set of values upheld by the social scientist must be made explicit to the reader. ${ }^{4}$

As aptly summed up by Stout (2010), in order to engineer the ideal-type method, first a specific social phenomenon of interest must be identified. Second, a culturally significant organising characteristic must be chosen and specified as the frame of reference. Third, the generic elements essential for identifying causal relationships must be identified; the set should be culturally significant, as comprehensive as possible, and the manner in which these elements are thought to be related must be explicated in a logical manner. Fourth, mutually exclusive meanings of each element must be interpreted so that the genetic character of the ideal-type is clear. These meanings must also be logical and coherent in their relationships with one another and plausible in comparison to experience (Stout, 2013).

The art of working out new ideal-types might be deemed to be a lost art rather than something into which contemporary PA scholars are engaging, but Stout and Love systematically resort to the use of ideal-typing to work out their ideal-type of 'integrative governance' as a synthesis of four primary governance approaches (Stout and Love, 2019, pp. 46-9 in particular). Their work is thus an example both of ideal-typing as a practised and contemporary art in public governance, and of a book-manifesto which makes explicit the philosophical foundations of the proposed argument, indeed in which philosophical knowledge underpins and informs the argument: an example of philosophy of public administration, in the framework worked out in Chapter 1 (incidentally it may be noticed my ontology is different from the authors', yet this consid- 
eration does not detract anything from my appreciation for writing one of the rare books in recent times proposing a philosophy of public administration).

Both ideal-types and utopias may be used for framing empirics and gaining insights, although ideal-types are more geared to theory building while utopias are also meant to arouse passions and social action for change towards a different state of affairs than the extant one; utopias are a radical way of utilising teleological thinking. Both are rather context-insensitive, but ideal-types are amenable to mental experimentation of what would happen when placed in context ' $A$ ' or context ' $\mathrm{B}$ ', while utopias set their own context, and replace the real ones. Utopias totally reverse the logic of path dependency; they embody the converse of historical institutionalism.

Both utopias and ideal-types are to be distinguished from the notions of 'model' and of 'paradigm'. A model can be defined as a selective reduction of reality in order to highlight key relations and connections for purposes of understanding and highlighting key causal relations as well as for guiding action. Models are ubiquitous in the study of PA; at times they aim at providing description, explanation and interpretation of administrative phenomena; other times they take up a normative and prescriptive thrust and aim at providing guidance for change and reform of public administration and management. The 'New Public Management' (Hood, 1991), the 'New Public Service' (Denhardt and Denhardt, 2001/2015), the 'New Public Governance' (Osborne, 2006, 2010), the 'Digital Era Governance' (Dunleavy et al., 2006), the Neo-Weberian State (Pollitt and Bouckaert, 2000/2011), the 'stewardship model' patterned on a revisited conception of the traditional British public administration (Rhodes, 2016), and so on, may be labelled as models (more or less internally consistent), with differential emphases and either leaning towards the descriptive and explanatory (descriptive-analytical models), or towards the prescriptive and normative (prescriptive models). Modelling, when it takes a normative thrust, is for action: it is a form of bracketing wider aspects of reality to focus action on those aspects that are causally more directly linked to the expected outcomes to be attained, purposefully forgetting that reality is more complex than what the model depicts (the main problem here lies in the fact that the forgotten part of reality sooner or later strikes back). When models also take up a normative dimension, they can be likened functionally to ideal-types and utopias in that they can be used as yardsticks for the critical analysis of the present situation in view of the pursuit of a travel - a reform trajectory - towards a more desirable destination (the obvious problem applies - desirable for whom? - which brings us back to the issue of the legitimacy of a governance system discussed in Chapter 5).

The notion of paradigm is pitched at a different level: a paradigm can be defined as a coherent pattern of core ideas and premises (assumptions or hypotheses) that governs scientific inquiry in the discipline at a given time: 
these are scientific paradigms (Kuhn, 1962; Riccucci, 2010). The notion of paradigm may also take a normative and prescriptive thrust, and thence in PA paradigms can be defined as sets of core tenets about how to organise the public sector. Drechsler has called attention to the significance of three main paradigms in PA, from a historical viewpoint: the Western PA paradigm (itself highly composite, and as a very minimum it should be distinguished Anglo-American PA from continental European 'Weberian' PA), the Confucian PA paradigm, and the Islamic PA paradigm. Over more recent centuries the (highly composite and varied) Western paradigm of PA has spread widely across the world, and in many respects it has been either coercively forced upon far-flung countries ('far' as seen from Western Europe, of course), or more or less willingly adopted by a number of countries because of its alleged qualities and attributes (one can think here of the Meiji revolution/ restoration in 19th-century Japan, or post-WWII processes of Westernisation of institutions and administration in South Korea). However, at least from a historical perspective, it is possible to observe that in the history of PA there have been at least two paradigms distinct and possibly 'alternative' to the Western one: the Confucian PA paradigm and the Islamic PA paradigm (the reader can find more on paradigms in PA and their usage in the postscript by Wolfgang Drechsler at the end of this book).

The border between 'model' and 'paradigm' may be not so easy to draw in practice. Some authors use the notions of paradigm to work out what they refer to as the contemporary 'public governance paradigms' (Andersen et al., 2020) to outline the features of doctrines about the reform of PA that we have in this book placed under the label of models (namely: New Public Management, Neo-Weberian State, Digital Era Governance, Public Value Management, and New Public Governance). Interestingly, they refer to public governance paradigms as 'quasi-paradigms': they retain the property of having a core of propositions (like a paradigm) and then a set of declensions of these core propositions can be made to flesh out the implications drawn from the core tenets. They are defined as 'relatively coherent and comprehensive norms and ideas about how to govern, organize and lead the public administration' and operationalised along five dimensions, defined as follows (Andersen et al., 2020): the extent of centralised control (the degree of recommended centralised control in the vertical chain of command); the emphasis placed on horizontal coordination (the degree of recommended horizontal interagency coordination and collaboration); the extent of use of value articulation (the degree to which public governance should be based on the articulation of public values); the extent to which it is resorted to the use of incentives (the degree to which public governance should be based on conditional positive and negative incentives); and the extent to which societal involvement is resorted to (the degree to which 
private for-profit or non-profit actors, including citizens, should be involved in public governance). According to the authors, these quasi-paradigms

[are not] paradigms in the Kuhnian sense of the term. However, we agree with Dunleavy and Margetts (2013) that public governance paradigms behave like ordinary paradigms in two important respects. First, they tend to have two levels, with an overall macro-level theory based on a few propositions that pull together and give direction to a wider range of supplementary concepts, detailed recommendations and preferred methods. Second, they develop in response to the problems of their predecessor, enter a period of relatively successful 'normal governance' and are problematized by the accumulation of problems to which they cannot provide an appropriate response. These resemblances to Kuhnian-type scientific paradigms serve to justify the notion of public governance paradigms. (Andersen et al., 2020, n.p.)

The introduction of the notion of 'quasi-paradigm' points to the consideration that the border between what constitutes a paradigm, on one hand, and what constitutes a model, on the other hand, may be porous, and intermediate concepts may be usefully wrought out and employed.

\section{PRACTICES: GOOD AND BEST}

Utopias, ideal-types, paradigms and models have crucial significance for the field of PA. However, words like utopias, ideal-types, paradigms and models have been looked at with suspicion in more recent times, partly as a sensible reaction to the failures of utopian-inspired social designs as well as (on a smaller scale) the apparent lack in fulfilling the expectations raised by models of PA reform like the New Public Management and a spate of others which followed suit. It is also partly as a reaction to reform models having been deemed to have fallen short of the expectations they raised that international organisations like the Organisation for Economic Co-operation and Development (OECD), which was very active in spreading 'global models of public management reform' during the 1990s, seem to have more recently orientated themselves towards the opposite approach, namely: the search for 'practices that work', which are often in practitioners' discourse called 'best practices'.

It seems that nowadays the practices approach - the extrapolation-based approach - is the prevailing one, notably in practitioners' discourse; its core tenet can be summarised as: 'rather than looking for new models (paradigms, ideal-types, utopias), we must search for practices that work and extrapolate them for replication (properly adapted) elsewhere'. There is much more than meets the eye, however, and the logic of best practices may be both seductive and highly misleading: first, truly 'best' practices are (very) rare and, second, 
the process of extrapolation and transfer of a practice (better: of the mechanisms that, incorporated into the practice, enable it to achieve certain results in the extant situation) to a target domain in order to replicate the results elsewhere is a major, complex process that may also lead to unexpected consequences (Bardach, 1994 and 1998, Chapter 2; Barzelay, 2007; Bretschneider et al., 2005; Ferlie and Ongaro, 2015, Chapter 8). It is for these reasons that many academics have claimed it better to conceive of the search for 'good' or 'smart' practices, rather than allegedly 'best' ones, that is, the search for practices that work well enough and can be replicated elsewhere, provided context and contextual influences are appropriately taken into account (Behn, 1991; Bardach, 1998; Barzelay, 2007; Ferlie and Ongaro, 2015).

The practices approach is appealing to practitioners, notably for its apparent sensibleness and 'pragmatism'. However, even when taking into account the warning against the seductions of naïve interpretations of the logic of 'best' practices, the practice approach may soon reach its limits. This occurs for a deeper reason: a practice-driven focus is unlikely to be equipped with the intellectual resources for escaping the traps of path-dependency. The practice agenda is inherently likely to be drawn into the scouting of the nearby terrain, and lose sight of the possible alternative views about PA and how the public sector could - and should - be organised. An approach self-confined to detecting practices that work and not complemented by the other approaches is unable to provide breakthrough solutions, or to furnish guidance on how to organise public governance that can anticipate major economic, societal or environmental changes (Pollitt, 2016b).

\section{TOWARDS AN INTEGRATED APPROACH: UTOPIAS, IDEAL-TYPES, PARADIGMS, MODELS, AND PRACTICES AS REPERTOIRE OF CONCEPTUAL TOOLS FOR THE BETTERMENT OF PUBLIC ADMINISTRATION}

The history of public governance and public administration has been made by the combined usage of different, complementary approaches; in this sense, nowadays partly neglected approaches like the usage of models, paradigms, ideal-types and utopias bear continued significance for the field of PA, as does the approach of practices extrapolation which seems to enjoy wide currency at the time the second edition of this book is being completed.

We might indeed see the whole gamut of these approaches as amenable to being ordered in function of the emphasis on either of the four causes first outlined by Aristotle (see Chapters 2 and 6). Those who ascribe to the Aristotelian approach stress that it is the joint application of the four causes to enable a full understanding of the phenomenon investigated. However, different agendas of 
research and epistemic approaches may place a different emphasis on either of the causes. We argue that the logic of the extrapolation of practices is primarily grounded in an emphasis on the efficient (and the material) cause. Conversely, utopias and to a certain extent ideal-types, paradigms and models embody teleological reasoning and take the final cause as the starting point of the inquiry. Finally, all these approaches are concerned with the formal cause (if you subscribe to the Aristotelian approach); however, we would put forward the tentative claim whereby the 'teleological' approaches - utopias and to a certain extent paradigm and ideal-types - strive to more directly define the 'nature' of the object they conceive and work out, that is, they are more interested with the formal cause (the essence or nature of the entity), whilst practice-based approaches are more focused on the apparent properties of the entity with an inherent orientation to disregard issues of 'essence' and 'form' (formal cause) as deemed to be ultimately of limited 'pertinence' and 'usefulness'.

We can hence now return to Figure 8.1, where we present utopias, paradigms, ideal-types, models, and practices as a range of conceptual tools which may also be seen in a combined way as a function of, first, the extent to which they take the move from actuality (what exists here and now) or potentiality (what may be brought to exist, but does not exist in actuality: it is not entelechy, in Aristotle's terminology, see Chapter 2); and, second, from the relative emphasis on either of the four causes that is placed when utilising these notions. Utopian approaches clearly take the move from the final cause, to then turn to tackling the issue of 'how to get there', that is, the enablers (material cause) and the forces (efficient cause) that may lead the system towards the end-goal (to the extent it is desirable - not dystopian - and taking into account that utopias perform more of an iconoclastic function as critique of the present state of affairs to identify ways forward than as a blueprint).

Approaches centred on learning from practices and extrapolating practices from one context for adaptation to another one take the move from the efficient cause (what is the mechanism that brings about the effect observed in the practice) and the material cause (what provides the conditions and enables something to happen).

The formal cause - what is the nature or essence of the object of investigation - is the starting point in modelling, ideal-typing and conceiving of paradigms, with an emphasis on 'what brings about certain effects' in modelling (efficient and material causes), and at least implicitly an emphasis on what the ultimate goal is (final cause) in ideal-types and paradigms.

\section{NOTES}

1. The network was later dissolved, and the Bertelsmann Foundation initiative is not to be confused with the homonymous EU programme. 
2. I'm indebted to Geert Bouckaert for this way of categorising utopias/dystopias.

3. Reference is specifically made to the 'European Perspectives for Public Administration: Futures Seminar' at KULeuven, Leuven, Belgium, 20-21 October 2016, held on the occasion of the Leuven city festival '500 YEARS UTOPIA' dedicated to Thomas More's Utopia published in 1516 in Leuven.

4. A lesson brilliantly taken up by the works of the Italian scholar Masini (1979), when he built up a theory of azienda which, although formally not inspired to ideal-typing as outlined by Weber, seems to contain many defining traits of it; in a similar vein on profiling the notion of the public sector as a system of interrelated organisations, see Borgonovi (1984). 